\title{
Control of Postpartum Haemorrhage with Uterine Balloon Tamponade Using Foley Catheter in a Rural Mission Hospital in Ebonyi State, Southeast Nigeria
}

\author{
Johnbosco E. Mamah ${ }^{1}$, Azubuike K. Onyebuchi' ${ }^{1}$ Zubaida Aliyu ${ }^{2}$, Vitus O. Obi ${ }^{1}$, \\ Chukwunenye Ibo' ${ }^{1}$, Chichetaram R. Otu ${ }^{1}$ \\ ${ }^{1}$ Obstetrics and Gynaecology Department, Federal Teaching Hospital, Abakaliki, Nigeria \\ ${ }^{2}$ Obstetric Division, Homerton University Hospital, London, UK \\ Email: *Johnbosco.mamah.pg78545@unn.edu.ng
}

How to cite this paper: Mamah, J.E., Onyebuchi, A.K., Aliyu, Z., Obi, V.O., Ibo, C. and Out, C.R. (2021) Control of Postpartum Haemorrhage with Uterine Balloon Tamponade Using Foley Catheter in a Rural Mission Hospital in Ebonyi State, Southeast Nigeria. Case Reports in Clinical Medicine, 10, 79-84.

https://doi.org/10.4236/crcm.2021.103009

Received: February 9, 2021

Accepted: March 9, 2021

Published: March 12, 2021

Copyright $\odot 2021$ by author(s) and Scientific Research Publishing Inc. This work is licensed under the Creative Commons Attribution International License (CC BY 4.0).

http://creativecommons.org/licenses/by/4.0/

\section{(c) (i) Open Access}

\begin{abstract}
Background: Postpartum haemorrhage is the leading cause of maternal deaths worldwide, the majority of which occur in low resource settings. Uterine atony is the commonest cause of postpartum haemorrhage. Uterine balloon tamponade (UBT) is an effective method of treating refractory postpartum haemorrhage. Aim: Commercial UBT devices are often not affordable and not readily available in rural settings. The aim of this paper is to report on three cases of postpartum haemorrhage successfully managed with uterine balloon tamponade using Foley catheters. Case Reports: We report on three patients with major obstetric haemorrhage from uterine atony who were successfully managed with uterine balloon tamponade using Foley's urethral catheter. The first two patients had primary postpartum haemorrhage while the third patient had significant bleeding during the surgical evacuation of the uterus for a molar pregnancy. In each case, uterine bleeding was refractory to pharmacologic uterotonics. They all had uterine tamponade with a Foley catheter with the dramatic resolution of their bleeding. Conclusion: In well-selected patients, uterine balloon tamponade with Foley catheter is cheap, arrests bleeding and prevents clinical deterioration among women with refractory postpartum haemorrhage, especially in low resource settings where commercial balloon tamponade may not be available or affordable.
\end{abstract}

\section{Keywords}

Balloon Tamponade, Foley Catheter, Management, Postpartum Haemorrhage, Rural Mission Hospital 


\section{Introduction}

According to data released by the World Health Organisation (WHO), postpartum haemorrhage remains the leading cause of direct maternal deaths globally [1]. Fuelled by inequality and inequity in the distribution and access to quality healthcare, the majority of these deaths occurred in the rural communities of developing countries [1] [2]. It is estimated that there is a 1 in 45 chance of dying from pregnancy-related complications in developing countries compared to 1 in 5400 in high-income countries [1]. Widespread implementation of effective measures aimed at controlling postpartum haemorrhage using pharmacologic uterotonic agents, uterine tamponade, vascular ligation and hysterectomy will ultimately lead to an overall reduction of maternal mortality [3].

Uterine atony is the commonest cause of primary postpartum haemorrhage [3]. Predisposing factors to uterine atony include precipitate or prolonged labour, injudicious use of oxytocics, multiple pregnancies, fetal macrosomia, grand multiparity, chorioamnionitis, retained pregnancy tissue, among others [3] [4]. These factors are significantly prevalent among pregnant women in sub-Saharan Africa where a substantial proportion of births are attended by unskilled birth attendants [5]. Appropriate management of uterine atony involves the use of effective uterotonic drugs, uterine massage, uterine balloon tamponade (UBT), uterine artery ligation and hysterectomy if all else fails [4] [6]. These potentially lifesaving interventions are often lacking in low-resource settings such as ours.

Uterine balloon tamponade has been reported as an effective and cheap intervention in the management of uncontrolled postpartum haemorrhage in cases where the use of uterotonics does not achieve the desired result [4] [7]. It works by exerting mechanical pressure on the bleeding venous sinuses in the placental bed and physically blocking their orifices. This will result in blood clot formation and cessation of bleeding [8]. Different commercial tamponade devices have been described, but they are often not available in rural communities, and where they exist, they are not affordable [9] [10]. We here report three cases of successful treatment of postpartum haemorrhage refractory to pharmacologic uterotonics using Foley's urethral catheter as a tamponade device in a rural mission hospital, Southeast Nigeria.

Case 1: Ms IN, a 20-year-old primigravida at 40 weeks gestation attended our facility in spontaneous labour. She achieved spontaneous vaginal delivery after about 6 hours of labour. The third stage of labour was managed actively with 10 international units of intramuscular oxytocin and controlled cord traction for delivery of the placenta, which was examined and assessed to be complete. She had an episiotomy which was promptly sutured, the estimated blood loss from delivery was about $200 \mathrm{ml}$. About 30 minutes after delivery, she was noted to be bleeding from the vagina. She had a brisk bleed of about $500 \mathrm{ml}$. She was examined and the uterus was not contracted. The uterus was massaged and five international units (IU) of oxytocin was administered intravenously. One litre of 
intravenous saline infusion and $40 \mathrm{IU}$ of oxytocin in $500 \mathrm{ml}$ of saline infusion were simultaneously commenced through separate intravenous cannulas. She continued to bleed and had a further $500 \mathrm{ml}$ blood loss. Uterine contraction remained suboptimal. She was transferred to the theatre for examination under anaesthesia. Bimanual uterine compression led to momentary cessation of bleeding which resumed after about 5 minutes. At this point, two size 22 FG Foley catheters were inserted through the vagina into the uterine cavity and inflated with $100 \mathrm{ml}$ of sterile water each. This promptly stopped the bleeding. A urine bag was attached to the catheters to monitor for ongoing bleeding. The catheters were removed after 6 hours with no further bleeding. She was discharged home after 24 hours. The total blood loss was about 1.7 litres. She remained clinically stable and subsequently had an uneventful puerperium.

Case 2: A 32-year-old grand multiparous woman was delivered of her 6th baby at home by a traditional birth attendant 2 hours prior to presentation. She was brought to our unit by relatives with ongoing vaginal bleeding and retained placenta. The traditional birth attendant had administered some medications and made several unsuccessful attempts to deliver the placenta. On presentation, Ms SA was in shock. Her haemoglobin was $60 \mathrm{~g} / \mathrm{l}$. She was immediately taken to the theatre and had a manual removal of placenta. The uterine tone was poor and she continued to bleed vaginally. Three size 22 FG Foley catheters were inserted into the uterine cavity and each inflated with $80 \mathrm{ml}$ of sterile water and the bleeding stopped. She received three units of red blood cells, and haematinics. The uterine catheters were removed after 12 hours. She was discharged home the next day.

Case 3: A 36-year-old para 3 was brought to our unit with heavy vaginal bleeding associated with the passage of blood clots and maternal collapse. Two weeks prior to presentation, she attended our unit with vaginal spotting and was diagnosed with molar pregnancy by ultrasound scan. She was 12 weeks pregnant. She declined referral to a tertiary centre and refused surgical evacuation of pregnancy tissue. She patronised a local patent medicine dealer where she was given some uterotonic injections which led to profuse bleeding. A point of care ultrasound scan showed significant retained products of conception. She was taken to the theatre for an emergency suction evacuation of the uterine cavity. She continued to bleed despite an empty uterine cavity. A size 22 FG Foley catheter was inserted into the uterine cavity, inflated with $100 \mathrm{ml}$ of sterile water and the bleeding stopped. She received blood products and made an uneventful recovery. She was referred to a tertiary centre for surveillance but did not attend. Histology report confirmed complete mole. She was lost to follow up.

\section{Discussion}

Globally, massive postpartum haemorrhage remains the most common cause of maternal mortality and significant morbidity [1] [2]. More than $90 \%$ of these deaths are estimated to occur in low and middle income countries [1]. Nigeria is 
one of the developing countries where maternal mortality remains a significant problem. A WHO study in 2015 estimated that Nigeria has a maternal mortality ratio of $800 / 100,000$ live births with an estimated 58,000 maternal deaths in the same year [11]. The study added that women in remote areas were least likely to receive healthcare and had a 1 in 22 chance of dying from pregnancy or pregnancy-related complications [11]. Rampant poverty, illiteracy, ignorance and the patriarchal cultural society are responsible for the propagation of this scourge [12]. Even where facilities exist, pregnant women are not able to afford needed healthcare services because healthcare is financed out of pocket and patients would rather patronize cheap traditional birth attendants and quacks, without minding its attendant consequences as reported in this case series [12] [13].

Uterine atony is recognized as the commonest cause of postpartum haemorrhage but other possible causes need to be excluded [3] [4]. Interventions for the management of postpartum haemorrhage from uterine atony include the use of uterotonics and uterine tamponade devices. Effective commercial tamponade devices such as the Bakri balloon, Rusch balloon catheter, and Sengstaken-Blakemore tube have been reported in different studies for the management of intractable uncontrolled postpartum haemorrhage with good results [4] [10] [14] [15]. These facilities are expensive and not readily available in the rural communities of Nigeria with high burden of adverse maternal outcomes from postpartum haemorrhage. Innovative improvise such as the use of a condom balloon catheter and Foley's urethral catheter has been reported with successful outcomes [16] [17]. Yaqub et al reported a 72.5\% efficacy of Foley catheter balloon tamponade in the management of postpartum haemorrhage among 50 patients at the Lady Willingdon Hospital Lahore [16]. This device was reported to be effective among 5 patients who had a vaginal delivery and 45 patients who were delivered by caesarean section [16]. In a similar study, Ali et all reported on the successful control of postpartum haemorrhage in 15 out of 17 patients who had elective caesarean sections for major placenta praevia [17]. Two patients had hysterectomy following persistent bleeding despite the insertion of the Foley catheter for uterine balloon tamponade [17].

We presented our experience with the use of two-way Foley's urethral catheters for uterine balloon tamponade (UBT) in the management of refractory postpartum haemorrhage with good results. Each of the patients presented with a major obstetric haemorrhage and was clinically unstable to allow for referral to the nearest tertiary centre given the bad terrain and poor availability of transport facilities. Moreover, our experience shows a strong aversion to attending "big hospitals" by patients due to economic reasons [13] [18].

We note that the Foley catheter is cheap, readily available and culturally acceptable to patients in rural communities. We found this device very effective in the management of primary and secondary postpartum haemorrhage where pharmacologic agents failed to control bleeding. Although not licensed for this indication, we report that the catheter balloon can take more than double the volume of fluid recommended for inflation and this is enough to exert adequate 
hydrostatic pressure needed to stop bleeding from the placental bed. This simple intervention does not require significant technical know-how and can make the difference between life and death for the patient. This can also obviate the need for laparotomy and possible hysterectomy in these patients which would be considered a reproductive failure given the cultural premium attached to possessing a uterus in our rural society [18].

In conclusion, we report that in resource constrained settings and in well-selected patients, uterine balloon tamponade with Foley catheter is a cheap, effective and safe tool in the management of refractory postpartum haemorrhage before resorting to invasive surgical interventions.

\section{Acknowledgements}

The authors wish to thank the management and staff of Mater Misericordiae Catholic Hospital, Afikpo, Ebonyi State Nigeria for the support in publishing this case series. The patients gave informed consent for the publication of this case series.

\section{Conflicts of Interest}

The authors declare no conflicts of interest regarding the publication of this paper.

\section{References}

[1] Say, L., Chou, D., Gemmill, A., Tuncalp, O., Moller, A.B. Daniels, J.D., et al. (2014) Global Causes of Maternal Death: A WHO Systematic Analysis. The Lancet Global Health, 2, E323-E333. https://doi.org/10.1016/S2214-109X(14)70227-X

[2] Souza, J.P. (2019) Application of Maternal Near-Miss Approach to Audits of Severe Maternal Complication in a Low Resource Country. An International Journal of Obstetrics and Gynaecology, 126, 1-57.

[3] Mavrides, E., Allard, S., Chandraharan, E., Collins, P., Green, L., Hunt, B.J., et al. (2016) On Behalf the Royal College of Obstetricians and Gynaecologists. Prevention and Management of Postpartum Haemorrhage. An International Journal of Obstetrics and Gynaecology, 124, e106-e149. https://doi.org/10.1111/1471-0528.14178

[4] Suarez, S., Conde-Agudelo, A., Borovac-Pinheiro, A., Suarez-Rebling, D., Eckardt, M., Theron, G., et al. (2020) Uterine Balloon Tamponade for the Treatment of Postpartum Haemorrhage: A Systematic Review and Meta-Analysis. American Journal of Obstetrics \& Gynecology, 222, 1-52. https://doi.org/10.1016/j.ajog.2019.11.1287

[5] Kwawukume, E.Y., Gosh, T.S. and Wilson, J.B. (1993) Maternal Height as a Predictor of Vaginal Delivery. International Journal of Gynecology \& Obstetrics, 41, 27-30. https://doi.org/10.1016/0020-7292(93)90150-U

[6] Burke, T.F., Danso-Bamfo, S., Guha, M., Oguttu, M., Tarimo, V. and Nelson, D.B. (2017) Shock Progression and Survival after Use of a Condom Uterine Balloon Tamponade Package in Women with Uncontrolled Postpartum Haemorrhage. International Journal of Gynecology \& Obstetrics, 139, 34-38.

https://doi.org/10.1002/ijgo.12251

[7] Burke, T.F., Ahn, R., Nelson, B.D., Hines, R., Kamara, J., Oguttu, M., et al. (2015) A 
Postpartum Haemorrhage Package with Condom Uterine Balloon Tamponade: A Prospective Multi-Centre Case Series in Kenya, Sierra leone, Senegal, and Nepal. An International Journal of Obstetrics \& Gynaecology, 123, 1532-1540. https://doi.org/10.1111/1471-0528.13550

[8] Vitthala, S., Tsoumpou, I., Anjum, Z.K. and Aziz, N.A. (2009) Use of Bakri Balloon in Post-Partum Haemorrhage: A Series of 15 Cases. Australian and New Zealand Journal of Obstetrics and Gynaecology, 49, 191-194. https://doi.org/10.1111/j.1479-828X.2009.00968.x

[9] Makin, J., Suarez-Rebling, D.I., Shivkumar, P.V., tarimo, V. and Burke, T. (2018) Innovative Use of Condom Uterine Balloon Tamponade for Postpartum Haemorrhage in India and Tanzania. Case Reports in Obstetrics and Gynaecology, 2018, Article ID: 4952048. https://doi.org/10.1155/2018/4952048

[10] Georgioua, C. (2009) Balloon Tamponade in the Management of Postpartum Haemorrhage: A Review. An International Journal of Obstetrics \& Gynaecology, 116, 748-757. https://doi.org/10.1111/j.1471-0528.2009.02113.x

[11] World Health Organization (WHO) (2015) Maternal Health in Nigeria: Generating Information for Action.

https://www.who.int/reproductivehealth/maternal-health-nigeria/en/\#: :text=In\%2 02015\%2C\%20Nigeria's\%20estimated\%20maternal,maternal\%20deaths\%20during $\% 20$ that $\% 20$ year.

[12] Meh, C., thind, A., Ryan, B. and Terry, A. (2019) Levels and determinants of Maternal Mortality in Northern and Southern Nigeria. BMC Pregnancy and Childbirth, 19, Article No. 417. https://doi.org/10.1186/s12884-019-2471-8

[13] Sageer, R., Kongnyuy, E., Adebimpe, W.O., Omosehin, O., Ogunsola, W.A. and Sanni, B. (2019) Causes and Contributory Factors of Maternal Mortality: Evidence from Maternal and Perinatal Death Surveillance and Response in Ogun State, Southwest Nigeria. BMC Pregnancy and Childbirth, 19, Article No. 63. https://doi.org/10.1186/s12884-019-2202-1

[14] Bakri, Y., B-Lynch, C. and Alouini, S. (2020) Second Generation of Intrauterine Balloon Tamponade: New Perspective. BMJ Innovations, 6, 1-3. https://doi.org/10.1136/bmjinnov-2019-000404

[15] Dumont, A., Bodin, C., Hounkpatin, B., et al. (2017) Uterine Balloon Tamponade as an Adjunct to Misoprostol for the Treatment of Uncontrolled Postpartum Haemorrhage: A Randomized Controlled Trial in Benin and Mali. BMJ Open, 7, e016590. https://doi.org/10.1136/bmjopen-2017-016590

[16] Yaqub, U., Hanif, A. and Annals, K. (2010) Balloon Tamponade with Foley's Catheter: An Effective Method of Controlling Postpartum Haemorrhage. Annals of King Edward Medical University, 16, 295-298.

[17] Ali, M.K., Abbas, A.M., Abdelbadee, A.Y., Shazly, S.A. and AbdelMagied, A.M. (2016) Use of Foley's Catheter Balloon Tamponade to Control Placenta Site Bleeding Resulting from Major Placenta Previa during Caesarean Section. Proceedings in Obstetrics and Gynecology, 6, Article 4. https://doi.org/10.17077/2154-4751.1305

[18] Ezechi, O., Fasubaa, O.B., Kalu, B.E., Nwokoro, C.A. and Obiesie, L.O. (2004) Caesarean Delivery: Why the Aversion. Tropical Journal of Obstetrics and Gynaecolo$g y, 21,164-167$. https://doi.org/10.4314/tjog.v21i2.14494 